\section{EL SINDICATO Y SUS RETOS ANTE LAS TRANSFORMACIONES ECONÓMICAS Y SOCIALES}

\author{
Rodrigo Vargas Ávila*
}

Fecha de Recepción: 15 de octubre de 2010

Fecha de Aceptación: 30 de noviembre de 2010 Artículo de Reflexión

\section{Resumen}

En este ensayo se analizan los principales retos que, como consecuencia de las transformaciones económicas y sociales, enfrenta el sindicato en la actualidad y algunas respuestas que podrían implementarse tendientes a la superación de la crisis por la que atraviesan.

\section{Palabras clave}

Sindicato, Trabajo, Globalización, Terciarización, Flexibilización.

\section{THE UNION AND ITS CHALLENGES BEFORE THE ECONOMIC AND SOCIAL TRANSFORMATIONS}

\begin{abstract}
In this paper will be analyzed the main challenges, as a result of the economic and social transformations, facing the Union in the current events and some answers that could be

* Abogado Especializado en Instituciones Jurídico Familiares de la Facultad de Derecho, Ciencias Políticas y Sociales de la Universidad Nacional de Colombia; Docente de la misma Universidad; Jefe del Área de Derecho Procesal de la Facultad de Derecho de la Universidad Militar Nueva Granada; Profesor de Derecho Procesal y Probatorio en esta última universidad; investigador en las áreas del Derecho Procesal, Probatorio y Derecho Privado; conferencista; miembro del Instituto Colombiano de Derecho Procesal; exmagistrado auxiliar del Consejo de Estado. Actualmente candidato a Maestría de la Facultad de Derecho de la Universidad de los Andes. rodrigo. vargas@unimilitar.edu.co; rva91@hotmail.com
\end{abstract}

implemented aimed at overcoming the crisis by the crossing.

\section{Key words}

Trade Union, Work, Globalization, Outsourcing, Easing

\section{INTRODUCCIÓN}

En este ensayo me propongo analizar los principales retos que, como consecuencia de las transformaciones económicas y sociales, enfrenta el sindicato en la actualidad y algunas respuestas que podrían implementarse tendientes a la superación de la crisis por la que atraviesan.

Los cambios se producen en tres escenarios: en el sistema económico, en el que la globalización ${ }^{1}$ definida como la

"transición del mundo hacia un nuevo sistema tecnológico, organizado en torno a la electrónica, la informática, la robótica y la biotecnología. (...) de cual emerge una sociedad articulada por el conocimiento. La especificidad de esta mutación radica en una cada vez más estrecha conexión entre avance científico-tecnológico y su aplicación a la esfera de la producción, distribución y consumo de bienes $y$ servicios. (...) el actual proceso ha comenzado a modificar los parámetros cruciales de la sociedad: la división y organización del trabajo, la socialización

\footnotetext{
"La crisis, que todos afirmamos como "global", ha provocado un efecto aparentemente contradictorio al estimular mecanismos diversos de defensa individual o de grupo, de colectivos de menor ámbito que el global. Seguramente a ello ha contribuido la ausencia, o la sensación de ausencia, de respuestas eficaces globales y solidarias. En todos los foros se considera la crisis como uno de los efectos de la globalización, pero las respuestas han significado (al menos en el ámbito sindical, aunque creo que no sólo en éste), la intensificación de aspectos corporativos en todos los niveles de producción y organización, lo que no deja de expresar un sentimiento de desconfianza respecto a soluciones globales, dando paso al "sálvese quien pueda". Boix, Isidor. "Construyendo el sindicalismo global”. En: Revista La Factoría. Número 9. Cataluña. p. 1.
} 
primaria y la educación, la estructura de la familia $y$ la comunidad, el funcionamiento de las empresas y los mercados, las comunicaciones y los intercambios, las formas de participación y la politica, y las propias maneras de representarnos el mundo"2.

Y la terciarización de la economía ${ }^{3}$, que consiste en que la población ocupada en el sector terciario (servicios) pasa a ser más numerosa que la del sector secundario (industria), y además, que la forma de trabajo propia de este sector se difunde por todos los demás, terciarizándolos.

Desde un enfoque económico se explica la terciarización a partir de la existencia de tres sectores:

E1 sector primario lo forman las actividades extractivas o productivas de recursos naturales: agricultura, ganadería, forestación, minería, pesca, etc.

El sector secundario es el que transforma los recursos naturales, o sea la industria y la construcción.

El sector terciario es una especie de bolsón en el que están todas las actividades comerciales y de servicios, desde las finanzas al comercio minorista, desde el transporte a las actividades jurídicas, pasando por los servicios gubernamentales, los servicios sociales (salud, educación...), a las personas (peluquerías, cines, etc.), etc.

Por ello se expresa que en las economías actuales a escala planetaria se observa un proceso

2 BRUNNER, José Joaquin. Globalización Cultural y Posmodernidad. FCE. Santiago. 1998. p. 69

3 "Uno de los patrones de cambio observados en la economía colombiana en la segunda mitad del siglo XX es el crecimiento en la participación de las actividades terciarias en el PIB. Este fenómeno se ha llamado terciarización y ha sido común tanto en países desarrollados como en aquellos en vía de desarrollo. En estos últimos, se pueden identificar una terciarización genuina, en la cual los servicios mejoran la competitividad sistémica de la economía, y una terciarización espuria, en donde los servicios tiene poco impacto en la competitividad del resto de la economía". BONET, Jaime. La terciarización de las estructuras económicas regionales en Colombia. Banco de la República-CEER. Bogotá. 2006. p. 3. de terciarizacion de la economía, lo cual trae como consecuencias el cambio de las relaciones entre sectores económicos y su contribución en la producción nacional.

La terciarización se refiere al "... crecimiento del peso económico del sector servicios. Es una tendencia del capitalismo contemporáneo que las actividades de servicios cada vez ocupan una proporción mayor de la población económicamente activa y realizan un porcentaje creciente del Producto (o sea de la producción de bienes y servicios). Cuando eso ocurre la economía de un país se "terciariza"...".

De otra manera, hay un crecimiento continuo del sector servicios, hasta situarse por encima del $60 \%$ del empleo total de esa economía y en cifras similares de aportación al PIB, para posteriormente tender a crecer más lentamente, lo cual muestra que la ocupación de la población en el sector servicios, pasa a ser más numerosa que la del sector industria, difundiéndose por todos los demás, constituyendo las principales transformaciones; en la empresa, que ha cambiado su configuración y se organiza a manera de red; y en el trabajo, que ahora es un universo heterogéneo y ha modificado profundamente su organización. Todos estos cambios requieren adaptaciones profundas del sindicato como sujeto político y como sujeto contratante de las relaciones de trabajo ${ }^{5}$.

$4 \quad$ STOLOVICH, Luis. La Tercerizacion. ¿Con qué se come?. Disponible en: http://www.clacso.org. [Citado: 13/12/2010].

5 "El sindicalismo está comprometido en una carrera de velocidad para adaptarse a una sociedad cuyos cambios rápidos y profundos amenazan su existencia. Hay que añadir a ello la crisis financiera y económica que golpea al mundo entero. Todo esto hace indispensable que nos interroguemos de nuevo y adaptemos permanentemente nuestro sindicalismo confederado a fin de que sea efectivamente portador de sus valores. Es ineludible tener en cuenta las situaciones individuales. La palabra individual liberada es fuente de emancipación. Pero si sólo es expresión de intereses particulares, puede resultar contraproducente porque pone en juego la solidaridad. Es preciso, pues, impulsar de nuevo una democracia social que parta de los individuos y sea productora del interés general". Grignard, Marcel. "El sindicalismo 
El mundo contemporáneo asiste no sólo a un nuevo orden económico mundial que se resume en el término globalización, sino también a una revolución tecnológica y a una crisis de los paradigmas para interpretar la realidad. En lo que respecta al ámbito laboral, hoy tenemos un tipo de empresa muy diferente a la fábrica modelo del siglo XX; un tipo de trabajador diferente al obrero, empleado o profesional que iniciaba su carrera laboral pensando en la estabilidad y la movilidad ascendente, y una normativa laboral que está siendo desbordada por la inestabilidad, la flexibilización de la empresa y del empleo y por la cultura y la ideología de empleadores y trabajadores.

En este desbordamiento de la normativa laboral hay cada vez más trabajadores, hombres y mujeres, calificados y no calificados y aun profesionales y técnicos que caen en la desprotección social, porque "no caben" en la normativa laboral, pero tampoco son capaces de insertarse individualmente en los mecanismos de mercado que les son adjudicados como vías de inserción individual.

Al debilitarse la idea de lo "colectivo" y las formas de expresión y de organización colectiva, los mecanismos clásicos y la institucionalidad laboral que estaban asociados a la sociedad industrial se muestran cada vez más débiles e ineficaces para cumplir con algunos mandatos de equidad y justicia social.

En América Latina este proceso de desestructuración se produce sobre institucionalidades secularmente débiles: sociedades que nunca llegaron a ser plenamente industriales y Estados que nunca llegaron a ser de Bienestar, pero que en ciertos momentos y ciclos históricos aspiraron a un modelo de desarrollo económico, social y político más integrador que excluyente, más democrático que autoritario.

en un momento crucial. jatreverse al cambio!" En: Revista La Factoría. Número 45. 2010. p. 2.
El enigma del siglo XXI es saber si el desarrollo económico, la democracia y la equidad son compatibles o si, por el contrario, los supuestos mandatos de la competitividad económica van a acentuar las tendencias negativas sobre los trabajadores, generando un núcleo reducido de personas plena y felizmente integradas al mundo globalizado y grandes mayorías desposeídas, inseguras e infelices que sostienen sobre sus hombros los índices de crecimiento económico ${ }^{6}$.

La estructura de la economía en Colombia presenta una tendencia hacia la tercierización, esto es, que si se observa la dinámica del producto según su composición sectorial, se observa como sectores agrupados en los servicios, tal es el caso del comercio y del sector financiero, así como los servicios comunales o gubernamentales, alcanzan más del $60 \%$ de la actividad económica. Por lo tanto, no es aventurado decir que el país va orientando sus esfuerzos hacia una economía de servicios, dejando de lado de manera explícita, la construcción de una base productiva que genere un volumen apreciable del valor agregado y que contribuya a la generación de empleo productivo y al mejoramiento del nivel de vida de la población.

Por otra parte, el panorama en América Latina y el Caribe, no es sustancialmente diferente. Así, en el plano laboral y social, los resultados de las reformas del decenio del noventa fueron poco alentadoras.

"El producto por trabajador creció a un ritmo muy bajo (0,21 por ciento anual entre 1990 y 2005), al tiempo que se observó un incremento del desempleo $y$ del empleo informal. En algunos países (los casos más notables fueron los de Argentina, Colombia $y$ Perú) se efectuaron reformas que flexibilizaron la contratación y el despido y, en muchos casos, se abandonaron mecanismos solidarios de la protección social tanto en relación con las pensiones como con la salud y la protección contra accidentes

6 ESPINOZA, Malva. Trabajo decente y protección social. Oficina Internacional del Trabajo. Santiago. 2003 
$y$ enfermedades profesionales, sin que aumentase correlativamente la cobertura del sistema. Se produjo un debilitamiento de algunas de las instituciones de relaciones laborales, en particular de la negociación colectiva (en términos de cobertura y de contenido) y de los medios tradicionales de solución de conflictos, medios que resultaron insuficientes y fueron cuestionados por ineficaces.

El argumento que justificó estos procesos estribaba en que todas estas instituciones laborales constituian elementos de «rigidez» que debian eliminarse para poder crear empleo formal. Sin embargo, luego de un decenio, la experiencia de varios países ha mostrado que pese a estas reformas no se logró no sólo incrementar el empleo formal, sino que, además, se produjo un incremento del desempleo y del sector informal, y se acentuó el fenómeno de la precarización de los empleos, asociada a la inseguridad de los ingresos, menor protección social, mayor rotación laboral, etcétera. Se ha argumentado ciertamente que estos malos resultados se deben a que las reformas no fueron completadas y se quedaron a mitad de camino. Sin embargo, no disponemos de indicio alguno de que mayor dosis de reformas de este tipo hubiera mejorado la situación. Por el contrario, la experiencia reciente hace pensar que quizás podrian haberla empeorado aún más"'.

En cuanto al comportamiento del mercado laboral, es claro que la proporción en que aumenta el producto, es superior al crecimiento de los puestos de trabajo a término indefinido y más grave aún, se evidencia un aumento del trabajo temporal después de la recesión de los años 98 y $99^{8}$.

Lo anterior indica que la recuperación de la actividad económica del país se ha dado a costa del deterioro del empleo y que son los ingresos salariales los que se han resentido en los últimos años. De igual forma, se mantienen

SOMAVIA, Juan. Trabajo decente en las Américas. Oficina Internacional del Trabajo: Informe del director. XVI Reunión Regional Americana. Brasil, mayo 2001. p. 11

8 La coyuntura laboral y sindical 2006- 2007 en cifras. Escuela Nacional Sindical (ENS). 2007. p. 4 altos índices de subempleo que refuerzan la interpretación de un crecimiento económico con salarios de mala calidad o en términos de la OIT, con poco aporte al trabajo decente que

"resume las aspiraciones de las personas en su vida laboral, aspiraciones en relación a oportunidades e ingresos; derechos, voz y reconocimiento; estabilidad familiar y desarrollo personal; justicia e igualdad de género. Las diversas dimensiones del trabajo decente son pilares de la paz en las comunidades y en la sociedad.

El trabajo decente refleja las preocupaciones de gobiernos, trabajadores y empleadores, que dan a la OIT su singular identidad tripartita. Puede ser sintetizado en cuatro objetivos estratégicos: principios $y$ derechos fundamentales en el trabajo y normas laborales internacionales; oportunidades de empleo e ingresos; protección y seguridad social; y diálogo social y tripartismo. Estos objetivos tienen validez para todos los trabajadores, mujeres y hombres, en la economía formal e informal, en trabajos asalariados o autónomos; en el campo, industria y oficina; en sus casas o en la comunidad".

En dicho sentido, pocas instituciones han vivido con el dramatismo que lo ha hecho el sindicato, las transformaciones económicas y sociales de los últimos años. Aunque por su propia naturaleza, el sindicato vive en el cambio social, del que es sin duda protagonista, el despertar del sueño keynesiano ${ }^{10}$-fordista ${ }^{11}$ que supuso la

\section{OIT. 1999. p. 4-5}

10 "Dentro de las teorías Keynesianas la política de pleno empleo era uno de los indiscutibles tópicos centrales. El gasto público, la protección de los mercados nacionales y su regulación eran absolutamente necesarios para dar empleo e incrementar la capacidad adquisitiva de los ciudadanos lo que generaría una mayor demanda y obviamente una mayor producción de bienes y servicios. Los sindicatos obtenian mayores salarios y a nivel macro planteaban reivindicaciones que conllevaran al fortalecimiento del bienestar de los trabajadores". SILVA ROMERO, Marcel. Tendencias contemporáneas de las convenciones colectivas y pactos sociales. En El derecho laboral que hereda el milenio. Universidad Nacional de Colombia. Facultad de derecho. Ciencias Políticas y Sociales. Bogotá. 1999. p. 169

11 "Los sindicatos significaron, históricamente, la expresión de una cosmovisión total y global de un grupo social diferenciado 
crisis económica de los setenta y la progresiva e inevitable asimilación de los cambios políticos, económicos, sociales y culturales que desde entonces se han sucedido, han forzado al movimiento sindical -como a otros agentes sociales y políticos, pero si cabe con mayor intensidad-, a revisar su patrimonio ideológico-cultural y a cambiar sus estructuras y estrategias.

\section{$\mathrm{Al}$ respecto señala la OIT como}

"ii]ndividualmente, los trabajadores carecen de poder. Su sindicación es lo que puede modificar esa situación. Los sindicatos son una vía mediante la cual los trabajadores pueden mejorar sus condiciones de vida y de trabajo y las de la sociedad en su conjunto. Esta es la razón por la que las organizaciones sindicales son vehículos de desarrollo. Son un medio por el que los trabajadores carentes de

que expresaba - a través de esta representación - su identidad y autonomía. (...).

El taylorismo fordismo multiplica el aprendizaje de roles productivos de naturaleza simple y relativamente heterogénea. El aprendizaje de los mismos se hace en el puesto de trabajo, comandado por la empresa. Cada vez más, el trabajo se constituye en una actividad dirigida al mundo fisico, que lo trata como un objeto al que hay que manipular para la obtención de alguna meta. El trabajo deja de ser una actividad que tiene sentido por sí misma para ser una actividad instrumental. Las relaciones con el mundo material se organizan de un modo utilitario. La racionalidad de estas relaciones instrumentales con el mundo material tiende a recortar los saberes productivos y las relaciones de interacción de los trabajadores y a favorecer el surgimiento de vínculos alienantes y destructores de su identidad y autonomía.

Simultáneamente, se ha producido el reconocimiento y la integración social de los asalariados como grupo diferenciado. Las instituciones que los representan se encuentran ante una actividad productiva que tiene dificultades en construir identidad y autonomía de clase y ante una sociedad que ya ha integrado socialmente al asalariado.

Los vinculos de identidad y pertenencia que se generaban entre las representaciones y los miembros de los grupos profesionales por el contenido del trabajo que ejercian y por el tipo de relaciones sociales e interacciones que establecian se debilitan para fortalecerse los instrumentales, aquellos que dicen más respecto de la utilidad de esta representación que de su capacidad de generar identidad o pertenencia". Catalano, Ana María. "La crisis de representación en los sindicatos. Del esencialismo de clase a la acción comunicativa". En: Nueva Sociedad. Número 124. Marzo-abril. 1993. p. 2-3. poder individualmente se convierten en actores en la sociedad capaces de luchar en pos de la justicia social en la economía globalizada y de la erradicación de la pobreza en todo el mundo" ${ }^{2}$.

Son muchos los desafíos que el sindicato ha afrontado y va a tener que afrontar, pero el protagonismo político, económico y social que ha adquirido, si éste persiste en su capacidad de adaptación, pude sacarlo avante ${ }^{13}$. Dos aspectos merecen destacarse al respecto; el primero, el notorio y constante descenso de la afiliación sindical que se ha presentado en los últimos años $^{14}$, tal descenso ha venido acompañado de una pérdida del poder sindical, primero porque la cobertura de la negociación colectiva ha disminuido ${ }^{15}$, y segundo porque el papel político del sindicato en el establecimiento de políticas,

12 OIT, Oficina Internacional del Trabajo. El papel de los sindicatos en la economía globalizada y la lucha contra la pobreza. Documento informativo. Coloquio internacional de trabajadores. Ginebra. 2005. p. 37

13 "[esta] tesis unívoca del debilitamiento sindical no explica realmente la variedad de las situaciones observadas sobre el terreno. La globalización ejerce sin duda efectos significativos sobre los sindicatos en los ámbitos del centro de trabajo, de la región, del sector, de la profesión o del país. Una tesis alternativa, la que mantiene este artículo, señala que el impacto real de la globalización varía según la capacidad que tengan los sindicatos de movilizar sus recursos de poder. Puesto que los límites de su poder están sufriendo una mutación en este nuevo contexto globalizado, el actor sindical debe volver sobre sus fuentes de poder con el fin de actualizarlas y renovarlas". LEVESQUE, Christian, et al. El poder sindical en la economía mundial. Manu Robles-Arangiz Institutua. Bilbao. 2004. p. 3.

14 Entre 2002 y 2009 al menos a 236 organizaciones se les negó registro sindical.

- La tasa de sindicalización en Colombia es del 4,2 \% del total de ocupados a diciembre de 2009.

- Hay 53.000 sindicalizados menos con respecto al 2002. Pasando en 2002 de 863.338 afiliados a 810.114 en el año 2010, datos que contradicen los informados por el gobierno y la ANDI que no cuentan con un sistema que procese esta información. Fuente: Escuela Nacional Sindical (ENS). 2010

15 En los 8 años de gobierno de Uribe la negociación de convenciones colectivas disminuyó. Entre 2001-2002 se negociaron 447 convenciones por año; y entre 2008 y 2009 se negociaron sólo 307, lo que representa una disminución del $31.2 \%$. 
en la reforma de los mercados de trabajo y en la reforma de los sistemas de bienestar, ha sido en general, con diversos grados de intensidad dependiendo de los países $^{16}$ y de la materia abordada, poco constante en los últimos años, en Colombia, por ejemplo, los trabajadores y organizaciones sociales no tienen asiento en ninguno de los organismos centrales que toman decisiones teóricamente concertadas en materia de política económica y social. La disminución en la tasa de sindicalización ${ }^{17}$, en

- Con respecto a la cantidad de trabajadores y trabajadoras que se benefician de algún convenio colectivo de trabajo, en los dos primeros años de este decenio se beneficiaron 176.140 promedio año.

- En los últimos dos años se beneficiaron 124.200 en promedio, lo que significa una reducción del 29.48\%. Fuente: Escuela Nacional Sindical (ENS). 2010.

En el período comprendido entre los años 1994 y 2007, el número de convenciones colectivas de trabajo ha disminuido de manera notoria. En efecto, mientras para el año 1994 se negociaron 496 convenciones colectivas, para el año 2007 se suscribieron apenas 254. En términos porcentuales esto significa una disminución del $60.71 \%$ al $54.86 \%$. Fuente: Escuela Nacional Sindical (ENS). 2008.

16 "Quizás el impulso más alentador para el movimiento sindical, después de muchos años a la defensiva, derive del surgimiento en varios países de gobiernos progresistas elegidos por su discurso antineoliberal. Algunos de ellos incluso contaron con el apoyo decisivo del movimiento sindical. Aunque la nueva coyuntura politica latinoamericana no cambiará automáticamente la dificil posición del sindicalismo, sí puede ayudar a oxigenarlo en algunos aspectos. Por ejemplo, a través de una valoración distinta $y$ de la aceptación del sindicalismo como un socio para aplicar politicas progresistas, mediante una mejora de la legislación laboral y del respeto a las normas laborales y la libertad de organización. Una experiencia interesante es la de Uruguay, donde las recientes reformas al marco laboral permitieron y estimularon un fuerte crecimiento de la tasa de sindicalización". Wachendorfer, Achim. "¿Hacia una nueva arquitectura sindical en América latina?". En: Revista Nueva Sociedad. Número 21. Septiembre octubre de 2007. p. 36.

17 "El interrogante que se plantea expresa una inquietud generalizada en el movimiento sindical de América Latina; el descenso, matizado pero severo, de las tasas de sindicalización en todo el continente, advertido en los últimos lustros al tiempo que se producía un acentuado proceso de desindustrialización $y$ de expansión del sector informal de la economía, constituyó el primer dato sólido que daba efecto, ha mermado la capacidad representativa del sindicato, y su capacidad de influencia política, por lo menos durante el pasado período de gobierno de Uribe Vélez ${ }^{18}$.

En el año 2007 y en comparación con el 2005, disminuyó el número de convenciones colectivas mientras los pactos colectivos, figura en general impuesta por los empleadores, crecieron de manera sustancial. En el período 1996-1997, 462.641 personas se beneficiaron de la negociación colectiva; en el periodo 2006- 2007, 176.948 se beneficiaron, lo que evidencia una significativa caída en la negociación colectiva y su cobertura, 285.693 beneficiarios perdieron sus garantías convencionales, aproximadamente un $62 \%$ de los beneficiarios de hace una década hoy están desprotegidos ${ }^{19}$.

soporte a la inquietud creciente. Al término de la década de los ochenta los factores de inquietud aparecen mucho más claros en términos no sólo de cobertura organizativa sino del deterioro de las conquistas sociales que de ordinario están asociadas a la presencia y acción del sindicalismo: el salario y la negociación colectiva". Sandoval M., Luís. "Sindicalismo y sectores informales". En: Revista Nueva Sociedad. Número 110. Noviembre -diciembre de 1990. p. 140-151.

18 "La política gubernamental de limitar la creación de sindicatos y su libre funcionamiento. Durante los cerca de seis años del gobierno Uribe Vélez se ha negado el registro de 236 nuevas organizaciones sindicales por parte del Ministerio de la Protección Social, lo que traduce que al menos 7.080 trabajadores en el país perdieron la posibilidad de sindicalizarse. Adicionalmente, se negaron 239 inscripciones de juntas directivas, subdirectivas y comités seccionales municipales, con lo cual, por actos administrativos, se menoscabó la organización sindical". En "La coyuntura laboral y sindical. hechos y cifras más relevantes 2007 - 2008". Fuente: Escuela Nacional Sindical (ENS). 2008. Sistema de información laboral y sindical "SISLAB". Medellín. p. 5.

19 "El último reporte sobre el tema publicado por la Escuela Nacional Sindical señala que en 2002 se contaba con 863.338 afiliados y en el año 2010 con 810.114 afiliados, lo que significa un decrecimiento del $6,1 \%$ en la afiliación sindical (53.224 afiliados)". Fuente: Central Unitaria de Trabajadores (CUT), et al.: Informe para la 99 Conferencia Internacional del Trabajo. Bogotá. 2010. p. 21. 
La situación anterior se puede contrastar con el papel político que deben cumplir los sindicatos. En efecto, la

"labor organizativa de los sindicatos constituye un esfuerzo clave con miras a la erradicación de la pobreza. Cuanto más organizados están los trabajadores, mejor pueden decidir su propio destino, al lograr comprender cabalmente su situación económica y politica. Dado que las redes sindicales se extienden desde la base compuesta por los afiliados hasta el plano internacional, se tienen en cuenta las inquietudes de muy diversos grupos sociales. Los sindicatos se crearon para defender los derechos económicos y políticos de sus miembros, sus familias y la sociedad en su conjunto. En aras de una defensa eficaz de los intereses de los trabajadores, es esencial que existan sindicatos sólidos, independientes y representativos. Al agruparse en sindicatos, los trabajadores pobres pueden liberarse de las actitudes de marginación y derrotismo; pueden pasar de ser victimas de la explotación a ser actores capaces de hacer progresar sus propios intereses" 20 .

El sindicalismo debe ser capaz de denunciar, de indignarse, de proponer, de negociar y de ejecutar sus experiencias.

Otro aspecto, no menos importante, tiene relación con la situación de los procesos de integración regional, en el que las organizaciones sindicales pueden adoptar dos posiciones. La primera es oponerse al proceso e intentar frenar cualquier eventual acuerdo. La segunda consiste en analizar el tema, fijar una postura y formular un planteamiento estratégico; es decir, participar del proceso de negociación e influir en su desarrollo.

En tres casos (las negociaciones de la UE con América Central, la CAN y el MERCOSUR), las organizaciones sindicales se han inclinado por la segunda alternativa. En general, se ha partido de una mirada crítica, pero con

$20 \quad$ El papel de los sindicatos en la economía globalizada y la lucha contra la pobreza. Trabajo citado. p. 39. el propósito de incidir en la negociación. El objetivo es alcanzar un posicionamiento y una acción sindical común a ambos lados del Atlántico. Para avanzar en ello, es conveniente preguntarse cómo debe ser enfocada la acción sindical, qué temas deben discutirse y con quiénes habría que hacerlo.

¿Cómo enfocar la acción sindical? Si las organizaciones sindicales pretenden generar algún tipo de influencia en el desarrollo de los procesos de integración y de negociación entre los bloques latinoamericanos y la UE, es necesario que actúen en forma conjunta, como región. No existe, al menos, alguna posibilidad, de conseguir resultados si cada central sindical nacional -suponiendo que las diferentes centrales de cada país se pongan de acuerdo- actúa en forma independiente. El interlocutor sindical debe ser regional y debe actuar con una sola voz $^{21}$.

Evitar la competencia entre sectores y entre países y actuar en conjunto es fundamental. En ese sentido, frente a las desventajas que implican estos procesos para el sindicalismo, la constitución y el fortalecimiento de sujetos regionales que se presentan como tales y negocian desde esa perspectiva es una posible ventaja. Y en esto no hay excusas: avanzar en este objetivo solo depende del propio movimiento sindical, de su inteligencia, su madurez y su espíritu de unidad. La fragmentación, nacional o regional, solo contribuiría a que los procesos de integración y negociación con otros bloques no reflejen los intereses y las propuestas de los trabajadores.

La estrategia del movimiento sindical es avanzar en ese camino de convergencia regional. En las tres subregiones existen organismos sindicales que agrupan a las centrales de los países miembros de cada bloque. Naturalmente, ellos están vinculados a los procesos de integración

${ }_{21}$ PADRÓN CURRAO, Álvaro. "Los acuerdos de asociación entre América Latina y la Unión Europea: el papel del movimiento sindical". En: Revista Nueva Sociedad. Número 211. Septiembre - octubre de 2007. p. 90 y s.s. 
regional, por lo que la composición y las líneas de acción de estos actores sindicales se vinculan estrechamente a la marcha de cada bloque regional. Sin embargo, en todos los casos se observa que no existe una dependencia institucional ni un reflejo automático, que estos organismos sindicales regionales no son una copia exacta de las estructuras de cada uno de los tres bloques.

\section{LAS TRANSFORMACIONES SOCIO- ECONÓMICAS: RETOS PARA EL CAMBIO}

El sindicato nace en el siglo XIX en la industria $^{22}$, para representar el trabajo en la fábrica y tutelar los intereses de un sujeto social típico: el trabajador manual, de sexo masculino, que trabajaba en la fábrica su entera jornada de trabajo a cambio de una retribución con la que se mantiene y mantiene a su familia, esto es, el trabajador común de la producción de masa. La identidad cultural y política del sindicato se forja en este contexto. La función del sindicato en este sentido ha sido la de conseguir, mediante sus instrumentos habituales de actuación -fundamentalmente, la negociación colectiva y la huelga-, sucesivas mejoras en las condiciones de trabajo y de vida de la clase trabajadora.

22 "En esta etapa, el sindicato era concebido sobre todo como instrumento de resistencia del oficio en la compraventa de la fuerza de trabajo, en la lucha por mejores condiciones de trabajo y en el mantenimiento del monopolio del oficio; de esta manera, también era visto como reproductor de la cultura del oficio (Mallet, 1978). Todo esto en un período de la producción capitalista en el que se mezclaban procesos manufactureros con otros maquinísticos, pero en los que el control capitalista sobre el tiempo de producción era limitado. Por otro lado, no habían surgido los sistemas de relaciones industriales, los sindicatos eran ilegales y, en general, no existían el derecho laboral, las instituciones de conciliación de los conflictos entre el capital y el trabajo, ni la seguridad social (Aglietta, 1978). Por ello su forma principal de lucha no fue la negociación colectiva sino la huelga de hecho y la insurrección". DE LA GARZA TOLEDO, Enrique. Alternativas sindicales en América Latina. Escuela Nacional Sindical. Documento número 53. Medellín. 2004. pp. 6 y s.s.
Pues bien, las transformaciones económicas y sociales acaecidas y las que están en curso, han modificado profundamente ese escenario natural del sindicato, obligándole a repensar y reformular sus estrategias y mecanismos de acción, su estructura y funcionamiento, su relación con los poderes públicos, con los empresarios, y con los propios trabajadores ${ }^{23}$. Como es apenas natural, las transformaciones son múltiples y de diversa índole, pudiéndose agrupar en función del escenario en el que se verifican de tres formas: aquellas que afectan al sistema económico en su conjunto, las que afectan a la forma y organización de la empresa, y las que se refieren al trabajo mismo, a su nueva composición y a sus nuevos sistemas de organización.

\subsection{El sindicato frente a los cambios económicos}

El primer desafío con el que se encuentran los sindicatos es un desafío general, porque interesa por igual a los Estados, a las empresas y a los ciudadanos: es la globalización. La extensión planetaria del dominio del mercado, la creación de un mercado de envergadura mundial afecta, desde luego, en primer lugar, a las empresas que quedan ahora sometidas a una concurrencia

23...conviene también señalar otro argumento actual en defensa de los sindicatos. Se refiere a la concepción del sindicato como una organización que puede servir para reducir los costes de transacción y las fricciones dentro del sistema productivo. Los sindicatos no sólo hacen huelgas. También sirven como cauce de expresión de los trabajadores y para resolver con rapidez, a través de procedimientos estandarizados, los conflictos cotidianos. Pueden disminuir también los costes de información, tanto para los trabajadores como para los empresarios (y reducir de este modo los costes de contratación y formación). Todo esto significa que la acción sindical puede lograr un aumento, sobre todo a largo plazo, de la productividad marginal de la mano de obra, $y$ que este aumento se traduzca en un aumento de la demanda de trabajo. Este argumento encierra probablemente una gran verdad empírica. Pero este efecto positivo es muy dificil de medir empiricamente; aunque no por ello debe pensarse que tenga poca importancia". ALBA, Alfonso. Teoría económica y análisis empírico de los sindicatos. Ministerio del trabajo y seguridad social. España. 1992. p. 441. 
global y deben organizar la producción de bienes y servicios a escala planetaria, pero en no menor medida interesa a los trabajadores y a sus organizaciones representativas por cuanto la globalización prefigura una nueva división internacional del trabajo y obliga al sindicato a pensar a escala global y a internacionalizarse. En muchos sectores productivos, sobre todo en el sector servicios (transportes, comunicaciones, energía, banca, etc.), tanto la propiedad como la gestión empresarial misma, trascienden claramente las dimensiones nacionales.

Se observa que:

"Ieln el escenario de la globalización de la economía, a la región latinoamericana se le presentan notables desafios. En la búsqueda de nuevos modelos de desarrollo económico, las propuestas de libre comercio e integración, se exhiben ante la mayoría de estos países, como opciones de altas complejidades. Frente al dilema de la pobreza, el desempleo, la flexibilización y desregulación de los mercados laborales, la inequidad y la vulnerabilidad de las instituciones; este continente concurre a un proceso con más desventajas de lo que suele imaginarse. Una agenda laboral que acompañe al proceso de libre comercio $o$ integración adquiere en el presente un carácter prioritario. Los beneficios que puedan derivarse de los modelos integradores de las economías latinoamericanas, están condicionados al tratamiento que se le otorgue al tema laboral" 24 .

E1 desarrollo de los mercados ${ }^{25}$ financieros, la introducción masiva de las tecnologías de

24 Mendoza, Carolina, et al. "Libre comercio e integración ¿dónde queda lo laboral?”. En: Gaceta Laboral. V. 12. Número 3. Maracaibo. 2006. p. 2 y 3.

25 "Lo mismo sucede con los mercados monetarios, cuya desregulación se ha llevado a cabo de manera sistemática y cuyos efectos devastadores sólo ahora empezamos a sentir. Privadas de esos pilares, las normas del libre cambio pierden su anclaje en la diversidad de las poblaciones, los territorios $y$ los productos. Podemos seguir durante cierto tiempo actuando como si el trabajo, la tierra o la moneda existiesen con independencia de los trabajadores, los medios naturales o la economía real, pero esas ficciones acaban forzosamente por derrumbarse, alcanzadas por el principio de realidad. Contrariamente a la fe ingenua de quienes adoran al la información y de las telecomunicaciones, el abaratamiento de los costos de transporte y de las comunicaciones han hecho factible un espectacular aumento de la movilidad del capital, y como consecuencia de ello, el que los procesos de deslocalización y relocalización productiva, a nivel regional y mundial, se multipliquen. Estos procesos afectan, en primer término, a las industrias de trabajo intensivas, respecto de las cuales los costos de producción, específicamente el costo de la mano de obra, son un factor determinante de la competitividad.

Con todo,

"Il]os analistas del movimiento social parecen coincidir en la apreciación de que la imposición generalizada del modelo neoliberal a partir de los años 80 del siglo pasado impactó sobre los trabajadores latinoamericanos bajo la forma de una nueva división internacional del trabajo, caracterizada por una menor demanda de materias primas $y$ productos primarios acompañada del mayor interés del capital por el dominio del agua, el gas, el petróleo y los biocombustibles. El abandono de los esfuerzos de industrialización ha aumentado la brecha tecnológica y rebajado por tanto la capacidad competitiva de nuestros países. La mano de obra barata se torna cada vez menos importante para atraer inversiones y hay un aumento desmedido de la deuda externa en la región. Para golpear más el futuro de estos países, la educación superior viene siendo sometida al esquema empresarial transnacional de las grandes corporaciones. Los sectores decisivos más golpeados por el cambio se relacionan con el enclave exportador, la industria $y$ los trabajadores públicos. La privatización de

mercado, el desmantelamiento de los derechos nacionales no permite en modo alguno que surja «el orden espontáneo del mercado", sino que se limita a socavar los cimientos institucionales de los mercados, pues no existe una economía de mercado, sino una diversidad de dispositivos jurídicos que instituyen diferentes tipos de mercado: diferentes por la indole de los productos y servicios intercambiados, $y$, asimismo, por las historias y las culturas jurídicas respectivas". Supiot, Alain. "Perspectiva jurídica de la crísis económica de 2008". En: Revista internacional del trabajo. Volumen 129. Número 2. 2010. p. 167 y s.s. 
empresas ha provocado la reducción del aparato industrial y del mismo Estado. Asistimos a una desenfrenada reducción del trabajo formal y progresivamente desaparecen el contrato colectivo y la estabilidad laboral" 26 .

La concurrencia entre territorios para atraer inversiones, para evitar o albergar deslocalizaciones, son habituales actualmente y, en este proceso, las actitudes del sindicato a la hora de hacer frente al fenómeno, de implicarse o desentenderse de la lógica empresarial, están siendo ya elementos estratégicos de primer orden. Los requerimientos que para el sindicato la globalización comporta son numerosos, pues obliga al sindicato a pensar globalmente, a asumir el hecho de la globalización a la hora de establecer reivindicaciones y estrategias, a emprender reformas estructurales que le permitan actuar eficazmente a nivel global ${ }^{27}$.

26 DELGADO, Álvaro. Luces y sombras del sindicalismo colombiano. Invitación a un debate posible. FESCOL. Bogotá. 2008. p. 3.

27 "La globalización no ha traído la prosperidad homogénea del mundo, por el contrario, los estándares laborales han ido hacia la baja aun en países desarrollados; tampoco las crisis económicas y financieras han sido abolidas con el libre mercado, por ende el problema del desempleo sigue latente. Teóricamente, la tesis del conflicto estructurado no ha sido rebatida, y la concepción de desarticulación de mundos de vida ignora que en el pasado tampoco existió una sociedad totalmente articulada, sobre todo en el siglo XIX, y que la desarticulación y la rearticulación parciales pueden ser una característica a más largo plazo de las sociedades de lo que suponen aquellas tesis (Hyman, 1996). En fin, que las prácticas sociales también pueden ser articuladoras más que concebir la articulación como condición dada". DE LA GARZA TOLEDO, Enrique. Alternativas sindicales en América Latina. Ob. Cit. p. 20.

"No son sólo las nociones de persona y de responsabilidad las que se hallan vaciadas de su contenido en el «mercado total». El propio derecho (al igual que la religión, las ideas o las artes) está considerado en él como un producto que compite a escala del mundo, donde tiene lugar la selección natural de los ordenamientos jurídicos más complacientes con el propósito de acumular ganancias financieras. (...) La representación jurídica del mundo arraigada en esta tendencia es la de un "mercado de productos legislativos» que brinda a los individuos libres plena capacidad de
En el período actual el sindicato no puede aspirar a incrementar simplemente las condiciones

acogerse a la legislación que más beneficiosa les sea. Para ayudar a los "consumidores de derecho" a escoger en ese "mercado de normas", el Banco Mundial publica todos los años, desde 2004, el "Doing Business", un informe en el que se valoran y comparan los derechos nacionales en función de su eficacia económica respectiva. Se funda en una base de datos cuantitativos cuya finalidad consiste en proporcionar "medidas objetivas" de la legislación de 178 países (a los que ahora llaman "economias»). Contiene, entre otras informaciones, indicadores cuantitativos de la «rigidez» de los derechos del trabajo de esos países. El informe Doing Business de 2005 contiene, por ejemplo, un capitulo sobre la contratación y el despido de trabajadores que calcula pormenorizadamente las trabas a la inversión impuestas en cada país por las normas del trabajo. La tabla comparativa de todos los derechos laborales del mundo se elabora en torno a los siguientes indicadores de la «rigidez del empleo»: dificultad de contratación; dificultad para alargar o disminuir la jornada de trabajo; dificultad del despido por motivos económicos y costo de la contratación y del despido. El lector habrá deducido fácilmente que los vocablos "dificultad" $y$ «rigidez» designan las normas laborales y el de "costo" no alude a veces al dinero, sino a los derechos que protegen a los trabajadores. El indice de "rigidez del empleo» inflige puntos de penalización a los Estados que reconocen demasiados derechos a los trabajadores, por ejemplo, dar cobertura social a los asalariados a tiempo parcial; fijar salarios mínimos que el Banco Mundial considera demasiado elevados (por ejemplo, estima que es demasiado elevada la cantidad de 20 dólares estadounidenses al mes para los países africanos); limitar la jornada máxima a 66 horas por semana; la obligación de dar un preaviso de despido, o los planes de lucha contra la discriminación racial o sexual. La instauración de ese "mercado de productos legislativos" debe llevar a la eliminación gradual de los sistemas jurídicos que menos se prestan a satisfacer las expectativas financieras de los inversores. La competencia que se hacen las empresas bajo la égida de los mercados financieros no debería, pues, limitarse a la esfera económica, sino convertirse en el principio vertebrador de la esfera jurídica. La instauración de este mercado del derecho terminará por ser incompatible con el imperio de la ley, pues dar a cada cual la libertad de escoger el ordenamiento jurídico que le convenga es antinómico con la sujeción de todos al imperio de la ley. Ello también es antinómico con la democracia, cuyo campo se reduce mecánicamente en los países cuyas legislaciones sociolaborales, fiscales y ambientales son puestas a competir entre ellas a escala del planeta". (...). Esta voluntad de despolitización ha llevado a que la mayoría de los economistas abandonen la tradición de «la economía politica» incardinada en el campo de las humanidades por una "ciencia económica» que imita a las ciencias exactas..." Supiot, Alain. "Perspectiva jurídica de la crisis económica de 2008”. Ob. Cit. p. 170-171. 
de vida o de trabajo por presión frente al Estado o por medio de la negociación colectiva, porque el sistema de relaciones industriales, así como el Estado en el que encontraba apoyo en términos de política económica y laboral, han cambiado $^{28}$. Hoy se enfrenta a un mundo en el que los Estados inducen la flexibilización ${ }^{29}$ de los sistemas de relaciones industriales y los mercados laborales, en el que reducen las protecciones de la seguridad social, en el que los mercados abiertos implican para las empresas tener niveles superiores en productividad y calidad, en el que la globalización supone entre otras cosas el posible traslado rápido de capitales entre países en busca de mejores condiciones para las empresas, utilizando la fragmentación de los procesos productivos y la subcontratación. Se trata de la crisis de un tipo de sindicato circulatorio y de Estado $^{30}$.

28 "Los sindicatos son unos de los actores principales en la concertación social y el éxito de la misma depende, entre otros, de la mayor unidad y/o cohesión representativa de las organizaciones sindicales y de su capacidad de aceptar compromisos de esta índole. Vale la pena subrayar la paradoja de que la consagración del sindicalismo como interlocutor creíble en materia económica y social ocurra precisamente en un período de crisis del sindicalismo, de desafección de la "base" y de contestaciones en cuanto a su representatividad. De todos modos, la experiencia muestra que no siempre resulta fácil, tratándose de políticas de rigor, llegar a un acuerdo tripartito. Y la tendencia reciente a la descentralización, la flexibilización y la desregulación, plantea nuevos problemas para los sindicatos y pone en duda, en ciertos casos, la utilidad de la concertación social". SPYROPOULOS, Georges. El Sindicalismo frente a la crisis: Situación actual y perspectivas futuras. CINTERFOR. Primera conferencia nacional del trabajo. Brasilia. 1994.

29 El concepto sirve para muchas cosas, pero esencialmente, muestra la ruptura del principio de continuidad de la relación laboral, estableciendo en su lugar, el de la precariedad y atacando frontalmente la estabilidad en el empleo.

30 "Los sindicatos no pueden limitarse estrictamente al ámbito ocupacional o laboral porque toda decisión política tiene consecuencias para los trabajadores, afecta sus salarios, prestaciones y condiciones laborales. E1 movimiento sindical ha mejorado sus condiciones de trabajo mediante la negociación colectiva pero es necesaria su participación en los órganos que
Consecuencia natural de la integración de los mercados y de la gestión de los servicios es la internacionalización de los conflictos laborales. Los conflictos de trabajo aumentan notoriamente su dimensión internacional, forzando al sindicato a adaptarse al nuevo escenario. Comoquiera que la empresa o el grupo de empresas concibe y planifica sus actuaciones globalmente, los conflictos se plantean, ahora, a nivel internacional, lo que obliga al sindicato a reformular sus modos de actuación. E1 sindicato como sujeto que limita su ámbito de actuación a nivel estatal se ve desbordado por la nueva dimensión de los problemas y la dimensión internacional de los conflictos ${ }^{31}$.

La composición de la economía, la pérdida de peso de la industria en el conjunto del sistema a favor del sector servicios, la terciarización de la economía, es un segundo elemento de preocupación para el movimiento sindical. El

formulan políticas, económicas y sociales. Tal participación exige que los sindicatos dediquen atención a problemas de intereses generales, políticos en el más amplio sentido del término y que puedan manifestar públicamente sus opiniones acerca de la política económica y social del gobierno, puesto que su misión fundamental es asegurar el desarrollo del bienestar social y económico de todos los trabajadores y de la comunidad". Suarez, Ernesto Rafael. "Participación en política de los sindicatos". En: Rodríguez -Quito. Número 28. Revista Trabajo y Derecho. Bogotá. 1994. p. 10.

31 "Ante estos riesgos, los trabajadores buscan conectarse de manera directa al mercado internacional, renunciando a sus antiguas reivindicaciones, reconvirtiendo su tradición de lucha frente al capital, y aún más, transformando su sentido de clase para adecuarse a los conceptos de mercado y de globalización que exigen una nueva mentalidad. Se han generado asi, importantes transformaciones en el mundo del trabajo, entre las que se destaca la fractura del movimiento sindical y de sus derechos laborales, entre los cuales sobresale la afectación del derecho de asociación a causa de los fuertes procesos de desregulación y flexibilización laboral que han dado al traste con el contrato de trabajo a término indefinido y han venido generalizando los contratos de trabajo a término fijo o las formas de contratación desprovistas de regulación laboral'. BEDOYA BEDOYA, María Rocio. El derecho de asociación sindical frente a la globalización. Universidad de Antioquia. Medellín. 2009. p. 42. 
sindicato se ha hecho en la industria y su cultura es, principalmente, una cultura industrial ${ }^{32}$. Pero la industria no ha hecho más que perder peso en el conjunto de la economía y del empleo y presumiblemente tal será su evolución futura.

Una industria que será -lo está siendo ya- mucho más terciarizada que la actual, pues cada día necesita más servicios para llevar a cabo su propia actividad productiva, tanto servicios tradicionales como avanzados.

La terciarización de la economía está transformando sustancialmente la forma del conflicto laboral y colocando al sindicato ante una realidad comprometida. La terciarización económica es la del conflicto mismo en un doble sentido: se produce, en primer lugar, una deslocalización del conflicto hacia el sector terciario, donde éste, por su repercusión pública, se revela más eficaz que en la industria; en segundo lugar,

32 "El movimiento sindical latinoamericano seguirá de esta forma atrapado entre los parámetros de la crisis económica y las politicas de ajuste, combinado con los intentos de los factores de poder de acortar sus espacios de acción.

El peso de estos factores negativos que recaen sobre el movimiento sindical se asocia con una serie de retos de tal envergadura $y$ actualidad que no permiten ninguna postergación. Ahora bien, si el movimiento sindical no logra confrontarse de manera efectiva y positiva a estos retos podría significar su segura marginación en un futuro no lejano. Uno de estos retos está relacionado con la búsqueda de soluciones concretas y prácticas para ver de qué manera el movimiento sindical logra construir una relación con el sector informal. Dentro de esta tarea, el movimiento sindical deberá repensar su concepción acerca del trabajo. Hasta hoy la preocupación casi exclusiva del sindicalismo ha sido el trabajo asalariado dentro de un esquema clásico cuyo eje es el obrero industrial, con el consiguiente criterio de que las demás formas de trabajo constituyen algo marginal. Pero si el movimiento sindical aspira a mantenerse como uno de los ejes de la sociedad civil deberá buscar nuevas definiciones y conceptos más amplios acerca del mundo y las relaciones de trabajo. Así en algunos países latinoamericanos, sobre todo en la región andina, donde existe una larga tradición de trabajo informal, ya se han realizado diversas e interesantes experiencias respecto a formas de comunicación eficaces entre grupos informales $y$ organizaciones sindicales". Wachendorfer, Achim. "Sindicalismo latinoamericano, un futuro incierto". En: Revista Nueva Sociedad. Número 110. Noviembre - diciembre de 1990. p. 80-91. en parte como consecuencia de la terciarización de la economía y en parte por los cambios que de ella han derivado para la propia morfología de conflicto, terceros, es decir, consumidores y usuarios, se ven comprometidos en el conflicto y utilizados como rehenes en las viejas y nuevas formas de acción colectiva. El conflicto es hoy más eficaz en la medida en la que a su lesividad económica añade una lesividad social, en tanto afecta a la ciudadanía y adquiere dimensión pública. Se trata, con todo, de un arma de doble filo, pues lo que resulta para la acción colectiva un instrumento de poder, puede serlo también de deslegitimación social. No obstante, es evidente que garantizar la solidaridad ante este conflicto terciario resulta, para el sindicato, más complejo y difícil porque la nueva forma del conflicto, es un nuevo factor que alimenta el pluralismo social.

Para Offe, el fin de la centralidad del trabajo como espacio estructurante de la sociedad se define a partir de dos grandes transformaciones. En primer lugar, el cambio en la estructura de la economía hacia el sector terciario en menoscabo del industrial y, en especial, de las ocupaciones: más cuellos blancos que azules; diferencias entre pequeñas y grandes empresas, y extensión de las ocupaciones no manuales en detrimento de las manuales, todo esto dentro de los procesos productivos y en los mercados de trabajo. En segundo lugar, el otro argumento, más teórico, remite a la fragmentación de los mundos de vida de los trabajadores, en particular entre el mundo del trabajo y el de la familia, el tiempo libre y el consumo; se trataría también de la pérdida de importancia del mundo del trabajo en la conformación de identidades y subjetividades. Es decir, la anulación de capacidades transformadoras amplias de los trabajadores, o de sujetos que tengan su centro en el trabajo, parte de la heterogeneidad de los obreros y, de manera más profunda, de la fragmentación de sus mundos de vida; esto último se convertirá en los posmodernos en obstáculo absoluto para la conformación de identidades 
amplias, no sólo de los obreros sino de todo sujeto social ${ }^{33}$.

\subsection{El sindicato y los nuevos modelos de empresa}

La segunda influencia para el sindicato está constituida por la transformación del modelo de empresa. Si el modelo fordista ${ }^{34}$, a imagen y semejanza del cual se organizó el sindicato, era la gran empresa industrial, en la que se forjaba la conciencia de clase, los intensos procesos de reestructuración de los años ochenta y noventa han puesto en entredicho la viabilidad de la misma y han dado carta de naturaleza a una empresa organizada en forma de red, que mediante el uso de nuevas tecnologías y el recurso intensivo del outssourcing ha alcanzado niveles de productividad y demostrado gran capacidad de adaptación a los requerimientos del mercado ${ }^{35}$.

Las estructuras productivas se organizan de forma más flexible. El cambio opera en doble

33 OFFE, C. Disorganized capitalismo. Polity Press. Cambridge. 1985.

34 "Tanto la empresa Taylorista como la Fordista se caracterizaban por la unidad estratégica y la concentración productiva. Todos los procesos productivos, y a menudo también la distribución de la producción, respondian a un mando único, y dentro de una misma empresa el colectivo laboral tendia a estar subordinado a un empleador único". Bronstein, Arturo. "Retos actuales del Derecho del Trabajo". En: Revista Latinoamericana de Derecho Social. Número 2. Enero - Junio de 2006. p. 4.

35 "Además, idealmente, el fordismo implica el control sistemático, por parte de una misma empresa, de todas las fases de acumulación, desde la producción de materias primas hasta el mercadeo [Siegel, 1988, 5]. Esta compleja división técnica del trabajo a veces se asocia a una división regional compleja dentro de o entre espacios económicos nacionales. (...) De hecho, los somete a su propia lógica, pues el predominio de la producción en serie significa que, en virtud de su impacto sobre la productividad y el crecimiento de la productividad, ésta es la principal fuente de dinamismo en una empresa o sector, y que se organizarán otros procesos $y$ actividades para apoyarla, mejorarla o complementarla". JESSOP, Bob. Crisis del Estado de bienestar. Hacia una nueva teoría del Estado y sus consecuencias sociales. Siglo del hombre. Universidad Nacional de Colombia. Bogotá. 1999. p. 21. sentido: de una parte, la estructura empresarial se fragmenta sustituyendo la gran empresa, por una serie de empresas menores con las que se establecen intensas relaciones de colaboración económica; de otra, se ajusta la estructura productiva y de servicios de la empresa a aquellos segmentos del ciclo productivo en los que puede aportarse alto valor añadido externalizando los demás.

En definitiva, tras un siglo básicamente caracterizado por una organización industrial basada en la integración vertical de la producción, las estrategias actuales se dirigen a desintegrar los procesos productivos, distribuyendo cada una de sus fases entre unidades empresariales menores y sustituyendo en la medida de lo posible el trabajo subordinado por redes contractuales de naturaleza mercantil.

Ese cambio en el modelo de empresa, en la medida en que supone la desintegración de la comunidad de trabajo, tiene importantes repercusiones sindicales. La división de la gran empresa que ha sido el ámbito natural de arraigo y desarrollo del sindicato, aquél en el que la formación de lo colectivo -la identificación de intereses comunes-, ha sido más visible y se ha hecho más factible. La sustitución de la gran empresa por numerosas y pequeñas nuevas empresas, supone para el sindicato el cambio de un escenario en el que su actuación ha sido relativamente fácil y exitosa por otro, el de la pequeña empresa, lleno de dificultades, en el que le ha sido siempre difícil penetrar. La pequeña empresa ha sido un terreno poco propicio para el sindicato, pues cuando en la empresa no se alcanza un determinado nivel de sindicalización, lo que suele ocurrir en ella, el empresario ignora al sindicato y se niega a negociar con él, prefiriendo la interlocución directa con el trabajador.

El nuevo modelo, de otra parte, en la medida en la que desintegra la comunidad de trabajo y cambia lo homogéneo por lo heterogéneo, enfrenta al sindicato a la diversidad y a la 
necesidad de componer un amplio espectro de intereses, si no siempre dispares, sí muy variados (territoriales, sectoriales, empresariales, etc.). La gran empresa favorecía la uniformización, los tratamientos normativos igualatorios, el convenio general; la nueva realidad empresarial favorece exactamente lo contrario, los tratamientos diversificados y la pluralidad de instrumentos de regulación. El reto para el sindicato es el de ser capaz de conciliar todos estos intereses crecientemente divergentes y llegar a una síntesis que permita representarlos adecuadamente ${ }^{36}$.

\section{$1.3 \mathrm{El}$ sindicato y los nuevos trabajos}

El desempleo masivo ha sido para el sindicato, como para la sociedad entera, un gran desafío. La fuerza del sindicato está estrechamente ligada al nivel de ocupación y durante décadas ha tenido que enfrentarse con niveles de desempleo generalizados y considerablemente

36 "La apertura económica también pone en riesgo la posibilidad de autodeterminación de las naciones, obligadas a abrir sus fronteras sin ninguna contraprestación, más allá de inscribirse a las leyes del mercado, de ser competitivas. Este riesgo se convierte en amena$\mathrm{za}$, ante la ausencia de un proyecto político nacional que lo encause en condiciones distintas en el escenario de la competencia global.

Ante estos riesgos, los trabajadores buscan conectarse de manera directa al mercado internacional, renunciando a sus antiguas reivindicaciones, reconvirtiendo su tradición de lucha frente al capital, y aún más, transformando su sentido de clase para adecuarse a los conceptos de mercado y de globalización que exigen una nueva mentalidad. Se han generado así, importantes transformaciones en el mundo del trabajo, entre las que se destaca la fractura del movimiento sindical y de sus derechos laborales, entre los cuales sobresale la afectación del derecho de asociación a causa de los fuertes procesos de desregulación y flexibilización laboral que han dado al traste con el contrato de trabajo a término indefinido y han venido generalizando los contratos de trabajo a término fijo o las formas de contratación desprovistas de regulación laboral". El Derecho de asociación sindical frente a la globalización. BEDOYA BEDOYA, María Rocío. El derecho de asociación sindical frente a la globalización. Universidad de Antioquia. Medellín. 2009. Ob. Cit. p. 42. altos. Con carácter general, su fuerza mengua cuando disminuye la demanda de trabajo y viceversa. Ocurre, sin embargo, que cuando el mercado de trabajo ha recobrado el pulso los trabajos demandados no responden al parámetro Taylor-fordista y ello redunda, de nuevo, en dificultades para la acción sindical ${ }^{37}$.

En efecto, frente a la homogeneidad del trabajo fordista, que facilitaba al sindicato la tarea de representar todo el universo del trabajo, la heterogeneidad del trabajo postfordista dificulta tales cometidos. El universo del trabajo es ahora mucho más rico del que era y el sindicato hoy debe representar a trabajadores sometidos a estatutos jurídicos muy diversos y con intereses muy plurales: trabajadores contratados a jornada completa y por tiempo indeterminado; trabajadores contratados a tiempo determinado, bien por la propia empresa o a través de una empresa de trabajo temporal, incluso por mediación de cooperativas de trabajo; trabajadores temporales sujetos a un contrato formativo; trabajadores de empresas contratistas (prestadoras de servicios o no); trabajadores autónomos con intensa dependencia económica, socios trabajadores, desempleados, etc. La segmentación del trabajo que resulta de esta variedad hace decididamente de éste una realidad menos compacta y uniforme de lo que lo era en el pasado, dificultando consiguientemente la tarea de representación de intereses del sindicato. El sindicato está ahora llamado

37 Se trataría en palabras de JESSOP de una transición al postfordismo, entendido como modo de regulación, en el cual se "introducen innovaciones y flexibilidades en ellado de lademanda en cada una de las áreas de regulación. (...) Así, la relación postfordista puede implicar una recomposición fundamental del trabajador colectivo (con una tendencia hacia lapolarización entre trabajadores calificados polivalentes y trabajadores no calificados, en contraste con latendencia fordista hacia la homogeneización en torno del trabajador masivo'semicalificado'); la organización de los mercados de trabajo internos y externos alrededor de diferentes formas de flexibilidad (funciones y habilidades, etc.); elpaso a la negociación colectiva a nivel de empresas $o$ de plantas; y nuevas formas de salario social". JESSOP, Bob. Crisis del Estado de bienestar. Hacia una nueva teoría del Estado y sus consecuencias sociales. Ob. Cit. p. 47. 
a articular y a conciliar toda esa diversidad de intereses.

Los cambios en la empresa y en los sistemas de organización del trabajo abundan en la misma dirección, es decir, la diversificación de situaciones e intereses y la revalorización de las aportaciones y aspiraciones individuales. Así, la nueva empresa flexible, los nuevos modos de producción, están modificando profundamente los contenidos del trabajo y exigiendo competencias y actitudes distintas en los trabajadores.

El trabajo cambia porque las profesiones ahora requeridas son las profesiones del saber que ejercen funciones más amplias, ricas y polivalentes, porque se fomenta el trabajo en grupo, porque se reduce la dependencia organizativa y jerárquica y porque se valora crecientemente la capacidad del trabajador de iniciativa, de adaptación a los cambios y de implicación en el proyecto empresarial. La exigencia empresarial de calidad total pasa necesariamente por un grado de implicación en la empresa del trabajador distinto del que era habitual en el taylor-fordismo, se requiere ahora un trabajador proactivo que comprometa su inteligencia al servicio del proyecto empresarial y eso exige intensos cambios en las relaciones de trabajo ${ }^{38}$.

Cambios que nuevamente están afectando a todos los sujetos de las relaciones de trabajo $\mathrm{y}$, desde luego, al sindicato ${ }^{39}$. De una parte, la nueva organización del trabajo en la empresa demanda actitudes sindicales más cooperativas y participativas, que como es obvio, requiere cambios en la cultura sindical y, probablemente, cambios institucionales que la favorezcan y hagan factible; de otra, el protagonismo que la nueva organización del trabajo otorga al

38 GONZÁlEZ ORTEGA, Santiago. "Tendencias contemporáneas del derecho del trabajo". En: SILVA ROMERO, Marcel (Comp.). El derecho laboral que hereda el milenio. Universidad Nacional de Colombia. Bogotá. 1999. p. 35-36.

$39 \quad$ Ibíd. p. 34. trabajador individual debe hacer al sindicato más sensible a las aspiraciones e intereses individuales, so pena de que el trabajador opte por un sindicato de grupo, o por preferir la interlocución empresarial directa. El sindicato ya no puede ser el paladín del igualitarismo, señaladamente del retributivo, porque debe representar intereses muy diversos -muchos de ellos individuales- que sólo desde la asunción de la diversidad pueden verse satisfechos ${ }^{40}$.

El sindicato no va a poder, como lo ha hecho en el pasado, dificultar las disparidades salariales porque hoy los diferenciales de productividad han aumentado y los trabajadores cualificados conocen las oportunidades de empleo que les ofrece el mercado. Ello va a llevarle tutelar de otra forma. Las nuevas tutelas deben ser menos igualitarias y responder mejor a la diversidad del trabajo. El sindicato se enfrenta a la doble grave exigencia de promover el desarrollo y las aspiraciones de los profesionales del saber e impedir la degradación de las condiciones de empleo y trabajo de los trabajadores ejecutores.

\section{EL PAPEL DEL SINDICATO ANTE EL NUEVO ESCENARIO}

Las principales funciones que el sindicato desempeña en una sociedad democrática ${ }^{41}$,

40 Bajo esta caracterización los sindicatos para los empresarios tienen un papel de "interlocutores sensibilizados con las necesidades de la empresa, partícipes de la idea de la confluencia de intereses, dispuestos a gestionar con el empresario las políticas de personal y partidarios de la idea del consenso y del conflicto expreso como una patología del sistema como alternativa a una oposición reivindicativa basada en la expresión del conflicto mediante la huelga $u$ otros medios de presión colectiva". Ibíd. p. 35-36.

41 "Si bien son conceptos diferentes, la democracia y la libertad están estrechamente relacionadas y junto con los derechos humanos constituyen un todo indivisible de cualidades que requiere la sociedad contemporánea para un mejor funcionamiento. Entre el conjunto de libertades, la libertad sindical ocupa un lugar preponderante. Su ausencia o incumplimiento dificulta el funcionamiento del sistema político y pone en peligro 
fundamentalmente son dos: i) En primer lugar, el sindicato tutela, como es obvio, los intereses de los trabajadores en la empresa, los representa frente al empresario o empresarios con el objetivo de mejorar sus condiciones de vida y trabajo; ii) En segundo lugar, el sindicato es un sujeto político que actúa ante los poderes públicos en defensa de los trabajadores a los que representa y que participa con ello, en el espacio de concurrencia que caracteriza a las sociedades pluralistas, en la definición del bien público. A este último papel se refiere, en nuestra Constitución Política, el Artículo 39 al señalar que "los trabajadores y empleadores tienen derecho a constituir sindicatos o asociaciones, sin intervención del estado". Al primero aluden los Artículos 56 y 55 superiores, cuando reconocen los derechos de huelga y negociación colectiva ${ }^{42}$.

la gobernabilidad y la paz social". OIT. Panorama laboral 2007 - América Latina y el Caribe -. Oficina Regional para América Latina y el Caribe. 2007. p. 30

42 "Dentro de su moderno contexto jurídico, la huelga que es explicada como un derecho individual de génesis colectiva, es reconocida dentro de nuestra Constitución como uno de los derechos fundamentales de libertad, enraizado en los soportes de los derechos sociales.

El derecho constitucional de huelga ha mostrado así, frente al progreso y el cambio, su carácter de instrumento de los grupos intermedios de los trabajadores, actores de la contienda jurídica destinada a integrar y corregir la actividad parlamentaria y gubernamental, orientada a conseguir la efectiva participación de los obreros en las organizaciones económica, social y política del Estado. Debe asimilarse, por lo mismo, que las luchas sociales van ligadas a una estrategia institucional coherente, que libere al movimiento obrero de su tradicional indiferencia hacia el orden jurídico vigente, ajustado esencialmente a los intereses de las oligarquías.

Sólo así se podrá reivindicar el prestigio de la vida democrática que sobre la plataforma de la organización republicana, hasta hoy sobre todo entre nosotros, tan sólo ha manifestado su vulnerabilidad, atrasos e insuficiencias. Dentro de nuestro sistema, y en el marco del derecho comparado, es ostensible la línea asumida incluso por la judicatura, de conferir a la huelga el carácter e importancia de todos los derechos constitucionales, tendencia que a nuestro juicio no podrá contener la oligocracia ni el nuevo liberalismo". Santos Azuela, Héctor. "El Derecho Constitucional de Huelga y el Estado Desertor". En: Boletín Mexicano
Por virtud del principio de libertad sindical se reconocen, entre otros, el derecho de trabajadores y empleadores sin distinción a constituir organizaciones y afiliarse a ellas, el derecho de las organizaciones de trabajadores y de empleadores de redactar sus estatutos y reglamentos y elegir libremente sus representantes, constituir federaciones y confederaciones y afiliarse a las mismas. De la misma manera, la libertad sindical conlleva el ejercicio de la acción sindical que se traduce en el derecho de las organizaciones a establecer libremente sus actividades y a formular su programa de acción para la defensa de intereses económicos y sociales que les son propios mediante todos los medios lícitos como el derecho de huelga, el cual hace parte del derecho general a la protesta y el derecho de negociación colectiva.

Con todo, las organizaciones sindicales coinciden en reconocer la crisis del movimiento sindical, especialmente en países donde el sindicalismo ha sido reivindicativo como en Colombia y ha sido fuertemente golpeado por la globalización económica y por las estrategias empresariales de flexibilidad y desregulación laboral, afectando los derechos de asociación y negociación colectivas; esto se expresa en una baja tasa de sindicalización, una casi inexistente negociación colectiva y múltiples obstáculos jurídicos y materiales para el ejercicio de las libertadas sindicales ${ }^{43}$.

\subsection{E1 sindicato como sujeto político}

Como sujeto político ${ }^{44}$ el sindicato ha venido desempeñando dos funciones principales: En primer lugar, la de negociar con las orga-

de Derecho Comparado. Nueva serie año XXX. Número 89. México. Mayo-agosto, 1997.

43 BEDOYA BEDOYA, María Rocio. El derecho de asociación sindical frente a la globalización. Ob. Cit. p. 47.

44 BAYLOS, Antonio. Democracia politica y sistema sindical: reflexiones sobre la autonomia del sindicato. Universidad de Castilla - La Mancha. 1999. p. 3-8. 
nizaciones empresariales y con los gobiernos las principales reformas de carácter social, a saber: las relativas al mercado de trabajo y a los sistemas de bienestar ${ }^{45}$. En segundo lugar, la de establecer, junto con las organizaciones empresariales, a menudo con soporte gubernamental, pactos de rentas, destinados a garantizar la estabilidad de salarios y precios y el poder adquisitivo de las retribuciones de los trabajadores.

En dicho sentido, el sindicato no es sólo una organización que representa al trabajo asalariado como agente económico a través de la contratación colectiva de la fuerza de trabajo, sino un actor social, que expresa la identidad social de los trabajadores en su conjunto y que se relaciona, por tanto, con el resto de los actores que interactúan en el sistema de relaciones laborales. De esta manera, analizar las relaciones que existen entre el sistema democrático y el sindicalismo permite señalar tres orientaciones básicas: i) como una relación de necesidad, puesto que la democracia política es un elemento connatural a la propia existencia del sindicato: sin democracia no hay acción sindical; ii) a la inversa, en la esencia de la democracia se inserta la actuación autónoma del sindicato: sin libre actuación del sindicalismo no hay democracia política. Lo que, por último, iii) lleva a plantear si se puede proyectar un cierto paralelismo entre la autonomía de la política y la autonomía sindical como elementos fundantes del sistema democrático, o lo que es lo mismo, cómo concebir el rol político del sindicato como elemento necesario de la democracia, no subordinado en su actuación a una predeterminación por lo político del marco de referencia global en el que se inserta su proyecto de transformación de la sociedad.

La primera cuestión que relaciona la democracia con el sindicato, tiene como génesis

45 GOUGH, Ian. Economía politica del Estado del bienestar. Blume. Primera edición Española. Madrid. 1982. p. 251 y s.s. comprender que en el origen y naturaleza del sindicato está inscrito un doble movimiento, antiautoritario y democrático, el cual actúa simultáneamente y da sentido a esta forma social. En efecto, históricamente es aceptado que se incorporó a los objetivos de la acción sindical un elemento directamente político, la construcción y defensa de las libertades públicas y la extensión de los derechos ciudadanos que configuran el eje central de los sistemas políticos democráticos.

En Colombia, el movimiento sindical ha sido un elemento principal en la lucha por la democracia, que perseguido sigue siendo la organización de mayor convocatoria en el país y ha demostrado con la victoria frente al referendo de Uribe que existe una fuerza social desconocida en los grandes medios de comunicación pero viviente en muchos corazones colombianos ${ }^{46} \mathrm{y}$, por lo mismo, se ha convertido en objetivo privilegiado del autoritarismo social de nuestra época.

La democracia es la condición de existencia del sindicato; en la Constitución se consagran tres tendencias diferentes para el tratamiento normativo y práctico que reciba el trabajo. Bajo la primera o teoría del conflicto, los sindicatos, el derecho de negociación colectiva y el derecho de huelga como elementos esenciales de la libertad sindical -entendido como derecho humano fundamental- tienen garantías en la Constitución pero dejando al legislador la expedición del respectivo estatuto del trabajo, sin que este cometido se haya materializado; la huelga es un método de lucha de los trabajadores; por la segunda o teoría del solidarismo, el Artículo $333^{47}$ de la Constitución ordena al

46 SILVA ROMERO, Marcel. Proyección de un siglo de Derecho Laboral Colectivo en Colombia. Universidad Nacional de Colombia. Bogotá. 2005. p. 384.

47 Al consagrase en este artículo como principios: 1) la actividad económica y la iniciativa privada; 2) la libre competencia económica; 3) la prohibición de obstruir o restringir la libertad económica y en el artículo 336 que, 4) enajenará o liquidará las empresas 
estado fortalecer las organizaciones solidarias que parten del criterio central de inexistencia de contraposición de intereses entre los propietarios de las empresas y los trabajadores, sino que sus intereses son unos mismos y es en su conjunto como deben organizarse para desarrollar la nación. Sin embargo, esta corriente solidarista en la práctica comprende el trabajo asociado, que ha minado el derecho laboral, específicamente en el derecho de asociación y la huelga. Por la tercera o teoría de la concertación, la Constitución señala la existencia de contradicciones entre los empleadores y los trabajadores pero que a nivel macro tienen intereses comunes, dando paso así a la constitucionalidad de los acuerdos tripartitos, donde se acuerdan políticas globales y se permite el desarrollo del conflicto en cada empresa, pero dentro de las orientaciones generales de los pactos. Los Artículos 60 concernientes al acceso democrático a la propiedad y concertación en el inciso segundo del Artículo 56 alcanzan su máxima expresión allíis.

Con todo, el sindicato es una formación que denota un pluralismo social que se ubica al lado de lo político, para configurarse ambos como elementos básicos de esa construcción compleja llamada Estado Social. El pluralismo social implica el reconocimiento de una esfera de autonomía que se traduce en la capacidad de dotarse de una propia estructura organizativa, dictar sus propias reglas de autotutela y ejercer una importante capacidad normativa sobre

monopolísticas cuando no sean eficientes, se levanto un gran obstáculo en contra del principio de libertad sindical. En efecto, el artículo 336 solamente señala que se respeten los derechos adquiridos, pero no las convenciones colectivas. Como consecuencia, resulta desprotegida la convención colectiva y los acuerdos entre empresas y sindicatos, manifestaciones del derecho de asociación; prima en estas materias el fin que el constituyente en el citado artículo le otorgó a las empresas como base del desarrollo.

48 SILVA ROMERO, Marcel. Proyección de un siglo de Derecho Laboral Colectivo en Colombia. Ob. Cit. p. 266. las relaciones laborales en un amplio sentido. Tal hecho político se traduce en términos jurídicos mediante el reconocimiento por el ordenamiento de esta posición institucional del sindicato y de su capacidad normativa y de solución de las controversias en las que está presente el interés del grupo social. A este hecho se vincula la determinación por el sistema jurídico de las reglas de selección y de fijación de interlocutores a través de la noción de la representatividad sindical y la tutela jurisdiccional de su dinámica. El sindicato se configura, desde esta perspectiva, como una instancia de emancipación y de participación en un proceso de igualdad social.

Desde la diferencia entre la igualdad formal entre las personas y la constatación de una desigualdad material basada fundamentalmente en la explotación del trabajo asalariado y en la libertad de empresa en un mercado competitivo, se asume en los textos constitucionales el compromiso de que los poderes públicos actúen nivelando paulatinamente esta desigualdad económica y social en una perspectiva de reformas graduales y progresivas. Es ciertamente un compromiso asignado a los poderes públicos, pero a cuyo objetivo se asocian formaciones sociales como el sindicato.

El sindicato, en cuanto representante de los intereses económicos de los trabajadores, resulta ser un elemento clave para el sistema democrático. Es decir que no hay democracia política sin la autonomía de formaciones sociales y lo que ello significa en referencia a la acción de representación y tutela de los intereses de los trabajadores en su conjunto, en cuanto miembros de un grupo social determinado. No existe, por tanto, democracia política plena sin que en ella se instalen los sindicatos como agregaciones de intereses jurídicamente preeminentes y políticamente relevantes que se configuran como instancias de emancipación social. Claro que esto coloca el tema de 
reflexión en un campo mas concreto, el de la posible convergencia entre lo sindical y lo político en una perspectiva de cambio social y de transformación del sistema económico y social en un sentido emancipatorio.

En esta nueva realidad, el sindicato que quiere expresar la identidad social de los ciudadanos cualificados por una situación de desigualdad económica y social, y que con su actuación pretende nivelar progresivamente hasta hacerla desaparecer ese desequilibrio social y de poder, tiene un proyecto autónomo de sociedad y de las reformas del sistema que se deben emprender, en una adecuada combinación entre objetivos a largo y a medio plazo ${ }^{49}$.

Es un proyecto general, porque afecta a la ciudadanía social entendida en un sentido lo más amplio posible, y reúne ante todo dos notas caracterizadoras de extraordinario relieve: autonomía respecto del proyecto político de sociedad que sostiene el partido político, lo que implica posiblemente amplias zonas de coincidencia, pero que no excluye la posibilidad de disenso puntual o de fondo con el programa del partido, que conduzca a una relación conflictiva, e independencia del proyecto sindical respecto de los procesos de representación política y sus avatares, en el doble sentido de no subordinar el programa de reformas al éxito electoral de las formaciones políticas más homogéneas ideológicamente con el enfoque sindical, ni de poner a disposición de la labor de oposición política la fuerza erosionante del gobierno que puede catalizar la acción reivindicativa sindical.

El sindicato deviene en verdadero sujeto político ${ }^{50}$, que debe negociar con el poder político

49 SANGUINETI RAYMOND, Wilfredo. "Libertad sindical y rol institucional de los sindicatos: anotaciones a dos décadas de vigencia del texto constitucional". En: Revista de Derecho Social No. 8. 1999. p. 35 y s.s.

50 PALOMEQUE LÓPEZ, Manuel Carlos. El sindicato como sujeto politico. Estudios de derecho del trabajo en su propio proyecto de sociedad, si bien intenta realizarlo con sus propios medios: negociación colectiva, huelga, autotutela de intereses en variadas formas, manifestaciones, información, participación institucional, etc. Ello hace que se amplíe necesariamente su campo de acción, que ahora se extiende a la concertación social de las políticas económicas y sociales, a la negociación política con el poder público de las líneas de actuación y de reforma de la sociedad y del Estado. De esta manera, es una necesidad del sistema sindical así constituido la emanación de reglas para determinar la interlocución en este nivel de la generalidad, del ámbito de la contratación de las medidas públicas en materia económica y social, en el sentido de impedir la arbitrariedad en la selección de los interlocutores sociales, limitando en consecuencia la libertad de elección, por el poder público o empresario, del sindicato con el que negociar en esos espacios. Este es el sentido de las reglas sobre la representatividad sindical, que inciden, respetándolo, sobre un fenómeno de pluralidad sindical, exigiendo un umbral de implantación social que es verificable de manera objetiva.

En síntesis, la autonomía del proyecto sindical así esbozada, necesita asimismo, determinadas condiciones para poder arraigarse en la práctica. La más clara, desde el punto de vista de los trabajadores, es la de la unidad de acción sindical, que presupone la incorporación de este elemento de generalidad y de representatividad tendencialmente global del conjunto de la ciudadanía social de un país determinado. Al menos este es un dato que resulta evidente desde la experiencia histórica colombiana ${ }^{51}$.

memoria del profesor Gaspar Bayón Chacón. Tecnos. Madrid. 1980. p. 555.

51 SILVA ROMERO, Marcel. Proyección de un siglo de Derecho Laboral Colectivo en Colombia. Ob. Cit. 


\section{BIBLIOGRAFÍA}

ALBA, Alfonso. Teoría económica y análisis empírico de los sindicatos. Ministerio del trabajo y seguridad social. España. 1992. p. 441

BAYLOS, Antonio. Democracia politica y sistema sindical: reflexiones sobre la autonomía del sindicato. Universidad de Castilla - La Mancha. 1999.

BEDOYA BEDOYA, María Rocio. El derecho de asociación sindical frente a la globalización. Universidad de Antioquia. Medellín. 2009.

BOIX, Isidor. "Construyendo el sindicalismo global". En: Revista La Factoría. Número 9. Cataluña.

BONET, Jaime. La terciarización de las estructuras económicas regionales en Colombia. Banco de la República - CEER. Bogotá. 2006.

BRONSTEIN, Arturo. "Retos actuales del Derecho del Trabajo". En: Revista Latinoamericana de Derecho Social. Número 2. Enero - Junio de 2006.

BRUNNER, José Joaquin. Globalización Cultural y Posmodernidad. FCE. Santiago. 1998.

CATALANO, Ana María. "La crisis de representación en los sindicatos. Del esencialismo de clase a la acción comunicativa". En: Nueva Sociedad. Número 124. Marzo-abril. 1993.

Central Unitaria de Trabajadores (CUT), et al.: Informe para la 99 Conferencia Internacional del Trabajo. Bogotá. 2010.

DE LA GARZA TOLEDO, Enrique. Alternativas sindicales en América latina. Escuela Nacional Sindical. Documento número 53. Medellín. 2004.

DELGADO, Álvaro. Luces y sombras del sindicalismo colombiano. Invitación a un debate posible. FESCOL. Bogotá. 2008

Escuela Nacional Sindical (ENS). 2010. 2008
La coyuntura laboral y sindical 2006-

2007 en cifras. 2007.

ESPINOZA, Malva. Trabajo decente y protección social. Oficina Internacional del Trabajo. Santiago. 2003.

GONZÁLEZ Ortega, Santiago. "Tendencias contemporáneas del derecho del trabajo". En: SILVA ROMERO, Marcel (Comp.). El derecho laboral que hereda el milenio. Universidad Nacional de Colombia. Bogotá. 1999.

GOUGH, Ian. Economía política del Estado del bienestar. Blume. Primera edición Española. Madrid. 1982.

GRIGNARD, Marcel. "E1 sindicalismo en un momento crucial. ¡atreverse al cambio!" En: Revista La Factoría. Número 45. 2010.

JESSOP, Bob. Crisis del Estado de bienestar. Hacia una nueva teoría del Estado y sus consecuencias sociales. Siglo del hombre. Universidad Nacional de Colombia. Bogotá. 1999.

LEVESQUE, Christian, et al. El poder sindical en la economía mundial. Manu Robles-Arangiz Institutua. Bilbao. 2004.

MENDOZA, Carolina, et al. "Libre comercio e integración ¿dónde queda lo laboral?". En: Gaceta Laboral. V. 12. Número 3. Maracaibo. 2006.

OFFE, C. Disorganized capitalismo. Polity Press. Cambridge. 1985.

OIT. Oficina Internacional del Trabajo. Panorama laboral 2007 - América Latina y el Caribe -. Oficina Regional para América Latina y el Caribe. 2007.

El papel de los sindicatos en la economía globalizada y la lucha contra la pobreza. Documento informativo. Coloquio internacional de trabajadores. Ginebra. 2005. 1999.

PADRÓN CURRAO, Álvaro. "Los acuerdos de asociación entre América Latina y la Unión 
Europea: el papel del movimiento sindical". En: Revista Nueva Sociedad. Número 211. Septiembre - octubre de 2007.

PALOMEQUE LÓPEZ, Manuel Carlos. El sindicato como sujeto político. Estudios de derecho del trabajo en memoria del profesor Gaspar Bayón Chacón. Tecnos. Madrid. 1980.

SANDOVAL M., Luís. "Sindicalismo y sectores informales". En: Revista Nueva Sociedad. Número 110. Noviembre-diciembre de 1990.

SANGUINETI RAYMOND, Wilfredo. "Libertad sindical y rol institucional de los sindicatos: anotaciones a dos décadas de vigencia del texto constitucional". En: Revista de Derecho Social No. 8. 1999.

SANTOS AZUELA, Héctor. "El Derecho Constitucional de Huelga y el Estado Desertor". En: Boletín Mexicano de Derecho Comparado. Nueva serie año XXX. Número 89. México. Mayo-agosto, 1997.

SILVA ROMERO, Marcel. Proyección de un siglo de Derecho Laboral Colectivo en Colombia. Universidad Nacional de Colombia. Bogotá. 2005.

convenciones colectivas y pactos sociales de las derecho laboral que hereda el milenio. Universidad Nacional de Colombia. Facultad de derecho. Ciencias Políticas y Sociales. Bogotá. 1999.

Sistema de información laboral y sindical "SISLAB". La coyuntura laboral y sindical.
Hechos y cifras más relevantes 2007 - 2008. Medellín. 2008.

SOMAVIA, Juan. Trabajo decente en las Américas. Oficina Internacional del Trabajo: Informe del director. XVI Reunión Regional Americana. Brasil, mayo 2001.

SPYROPOULOS, Georges. El Sindicalismo frente a la crisis: Situación actual y perspectivas futuras. CINTERFOR. Primera conferencia nacional del trabajo. Brasilia. 1994.

STOLOVICH, Luis. La Tercerizacion. ¿Con qué se come? Disponible en: http://www.clacso.org. [Citado: 13/12/2010].

SUÁREZ, Ernesto Rafael. "Participación en política de los sindicatos". En: Rodríguez-Quito. Número 28. Revista Trabajo y Derecho. Bogotá. 1994.

SUPIOT, Alain. "Perspectiva jurídica de la crísis económica de 2008". En: Revista internacional del trabajo. Volumen 129. Número 2. 2010.

WACHENDORFER, Achim. "¿Hacia una nueva arquitectura sindical en América latina?". En: Revista Nueva Sociedad. Número 21. Septiembre - octubre de 2007.

"Sindicalismo latinoamericano, un futuro incierto". En: Revista Nueva Sociedad. Número 110. Noviembre - diciembre de 1990. 
